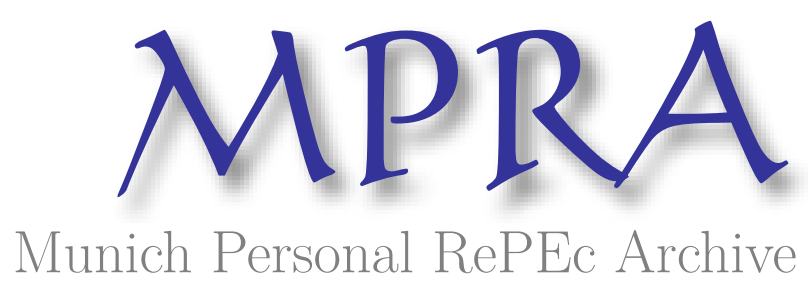

\title{
On contractual solutions to hold-up problems with quality uncertainty and unobservable investments
}

Schmitz, Patrick W.

2010

Online at https://mpra.ub.uni-muenchen.de/23157/

MPRA Paper No. 23157, posted 09 Jun 2010 03:12 UTC 


\title{
On contractual solutions to hold-up problems with quality uncertainty and unobservable investments
}

\author{
Patrick W. Schmitz* \\ University of Cologne, Germany, and CEPR, London, UK
}

\begin{abstract}
Consider a seller and a buyer who write a contract. After that, the seller produces a good. She can influence the expected quality of the good by making unobservable investments. Only the seller learns the realized quality. Finally, trade can occur. It is always ex post efficient to trade. Yet, it may be impossible to achieve the first best, even though the risk-neutral parties are symmetrically informed at the contracting stage and complete contracts can be written. The second best is characterized by distortions that are reminiscent of adverse selection models (i.e., models with precontractual private information but without hidden actions).

JEL classification: D86, D23, D82
\end{abstract}

Keywords: Hold-up problem; hidden action; hidden information; common values

* Tel.: +49221470 5609; fax: +49221470 5077.

E-mail address: patrick.schmitz@uni-koeln.de.

Address for correspondence: University of Cologne, Wirtschafts- und Sozialwissenschaftliche Fakultät, Staatswissenschaftliches Seminar, Albertus-Magnus-Platz, 50923 Köln, Germany. 


\section{Introduction}

The so-called hold-up problem, according to which parties may have insufficient incentives to make relationship-specific investments in the absence of contractual safeguards, is a central ingredient of the property rights approach to the theory of the firm. ${ }^{1}$ Several authors have investigated whether hold-up problems can be solved by writing suitable ex ante contracts. $^{2}$ The present paper adds to this literature by considering a novel variant of a hold-up problem in which the investing party has private information about a quality parameter that directly enters its trading partner's utility (i.e., there are common values).

Specifically, consider two risk-neutral parties, a (potential) buyer and a (potential) seller. When the parties first meet, they are still symmetrically informed, and there are no relevant wealth constraints. The parties can write a complete contract regarding the terms of trade of a good that the seller produces after the contract is written. While producing the good, the seller can make unobservable relationship-specific investments that stochastically influence the quality of the good. Only the seller learns the realized quality. Finally, the good can be exchanged and payments can be made according to the contract. While it is always ex post efficient to trade, the seller can consume the good herself when no trade occurs, and both parties prefer to consume a good that has a high quality.

Can the parties implement first-best effort and trade levels by writing an appropriate contract? If not, what does the second best look like? At first sight, one might suspect that the answers to these questions should be well known, because the problem seems to be one of the most basic settings a contract theorist could imagine. However, to the best of my knowledge,

\footnotetext{
${ }^{1}$ See the seminal contributions of Grossman and Hart (1986) and Hart and Moore (1990); see also Hart (1995) for a comprehensive exposition. While the property rights approach was developed to discuss vertical integration in the context of private firms, in the meantime it has also been fruitfully applied to analyze the pros and cons of privatization, see e.g. Hart et al. (1997) and Hoppe and Schmitz (2010a).

${ }^{2}$ See e.g. Hart and Moore (1988, 1999), Rogerson (1992), Maskin and Tirole (1999), Tirole (1999), and Hart (1995, ch. 4). See also Hoppe and Schmitz (2009) for the first study that investigates experimentally whether contracts can solve the hold-up problem.
} 
this simple problem has not yet been analyzed in the literature. It turns out that the model has some interesting properties that might make it a useful building block in future contract-theoretic research.

Specifically, the first best could clearly be achieved if effort were verifiable (the parties would agree to always trade and contractually prescribe the ex ante efficient effort level). Moreover, if effort were hidden but quality were verifiable, the first best could also be achieved (the parties would make the seller a residual claimant). Yet, we will see that it is impossible to simultaneously achieve ex post efficiency (i.e., always trade) and to implement high effort when effort is a hidden action and quality is private information of the seller. The impossibility result is very simple to prove but novel.

One of the most famous impossibility results in the contract-theoretic literature is due to Myerson and Satterthwaite (1983). ${ }^{3}$ They show that in general it is impossible to achieve ex post efficient voluntary trade when the buyer and the seller have independently distributed private information about their types, provided that it is ex ante uncertain whether or not the good should be traded. ${ }^{4}$ However, their impossibility result does not hold if the parties can write a contract ex ante (i.e., before they learn their types), as has been shown by d'Aspremont and Gérard-Varet (1979), Arrow (1979), and Crémer and Riordan (1985). Another celebrated impossibility result is Akerlof's (1970) "lemons" problem (see also Samuelson, 1984, and Myerson, 1985). In this problem, there are common values; i.e., the seller has private information about the quality of the good, which determines both the seller's and the buyer's valuation. Even though it is common knowledge that the buyer's valuation is always larger than the seller's valuation,

\footnotetext{
${ }^{3}$ See also the two-types version in Matsuo (1989), that captures the economic essence of the impossibility result in an accessible way. For generalizations of the impossibility result, see Krishna and Perry (1998) and Williams (1999). Moreover, see Klibanoff and Morduch (1995) for a related impossibility result where only one party has private information.

${ }^{4}$ On possibility and impossibility results in frameworks with precontractual private information, see also Cramton, Gibbons, and Klemperer (1987) and the more recent work by Schmitz (2002a), Schweizer (2006), Grüner (2008), and Segal and Whinston (2010).
} 
it may be impossible to achieve ex post efficient voluntary trade. Yet, this impossibility result also does not hold when the contract is written before the quality is realized (the parties would then simply agree to always trade).

Another impossibility result that is related to the one presented here is due to Schmitz (2002b). In that model, only the buyer learns his valuation after the seller has invested unobservable effort. Hence, the impossibility result obtained there does not involve any common values. Moreover, it is weaker than the one in the present paper, because it crucially relies on the assumption that there is no third party who could act as a budget breaker. ${ }^{5}$ This assumption may be difficult to justify in a setting that otherwise assumes complete contracting. ${ }^{6}$

An important advantage of the impossibility result in the present paper in comparison to impossibility results that rely on precontractual private information is the fact that here it clearly makes sense to look for the second best. As has been discussed in Fudenberg and Tirole (1991, p. 289), the second-best (i.e., ex ante optimal) contract in a model with precontractual private information such as Myerson and Satterthwaite (1983) is difficult to interpret, because it is unclear why the parties should be interested in maximizing their ex ante expected total surplus when they meet after they have already learned their types. ${ }^{7}$ In these models, the bargaining protocol of the contract negotiation stage will determine not only the division of the cake, but also the size of the cake.

In contrast, in the present model the parties are still symmetrically informed when the contract is written. Hence, regardless of the bargaining protocol, they will agree on a contract the maximizes the expected total

\footnotetext{
${ }^{5}$ Another well-known impossibility result that relies on the assumption that there is no third party is Holmström's (1982) moral-hazard-in-teams problem. In the deterministic version of his model, the first best could even be achieved in the absence of a budget breaker, if the parties could commit to burn money off the equilibrium path.

${ }^{6}$ Other reasons why the first best might be impossible to achieve that have been discussed in the complete contracting literature include risk aversion and wealth constraints, on which the present model does not rely. See Laffont and Martimort (2002) for an excellent textbook exposition of the traditional principal-agent theory.

${ }^{7}$ Recall that they would implement the first best if they met already before they learned their types.
} 
surplus. The parties' bargaining powers determine only the division of the cake, but not its size. Therefore, the second-best analysis is easier to justify in the present setting.

Interestingly, it will turn out that the second best is characterized by distortions that are reminiscent of models with precontractual private information (i.e., adverse selection). In particular, while trade is always ex post efficient when the quality is low, there is a downward distortion of the trade level when the quality (and thus the seller's opportunity cost) is high, provided that high effort is implemented. In contrast, if the seller's effort costs are sufficiently large, then low effort is implemented but ex post efficiency is achieved.

The present paper is related to the literature on contractual solutions to the hold-up problem. ${ }^{8}$ In particular, Rogerson (1992) considered a complete contracting model in which the parties can commit not to renegotiate and showed that the first best is achievable, even if the parties have private information (see also Konakayama et al., 1986, and Hermalin and Katz, 1993). Yet, he considered investments with no direct externalities and he assumed private independent types, ${ }^{9}$ while the present paper considers the case of common values. In an important paper, Che and Hausch (1999) have shown that if the parties can commit not to renegotiate, then the first best can be achieved even if the seller's investment influences the buyer's valuation. However, Che and Hausch (1999) consider the case of symmetric information, while in the present paper the seller obtains private information about quality and thus the first best cannot be achieved despite commitment. ${ }^{10}$ Finally, the hold-up problem is a central ingre-

\footnotetext{
${ }^{8}$ See Schmitz (2001) for a more extensive survey of this literature. More recent contributions to the literature highlighting the relevance of hold-up problems in various contexts include e.g. Guriev (2003), Rosenkranz and Schmitz (2003), Kessler and Lülfesmann (2006), Annen (2009), Bester (2009), Froeb and Ganglmair (2009), Stremitzer (2010), and Hoppe and Schmitz (2010b).

${ }^{9}$ See also Farrell and Gibbons (1995), who identify a trade-off between information revelation and investment incentives. Yet, their model is driven by precontractual private information. See Schmitz (2008c) for a hold-up problem with endogenous information acquisition.

${ }^{10}$ If renegotiation cannot be ruled out and the seller's investment influences the buyer's
} 
dient of the incomplete contracting literature, where the enforceability of some contractual clauses (e.g., clauses that rule out future renegotiations) or even of all contractual arrangements is ruled out by assumption. ${ }^{11}$ The most prominent application of incomplete contracting is the property rights approach to the theory of the firm. While most papers in this literature assume symmetric information, Schmitz (2006) has recently incorporated hidden information into Hart's (1995) property rights model. ${ }^{12}$ Yet, this paper did not consider the case of common values.

The remainder of the paper is organized as follows. In section 2, the basic model is introduced. In the basic model, it is always ex post efficient to trade. Nevertheless, it is shown in section 3 that the first best cannot be achieved whenever it is required to implement high effort. The second best, on which the parties in the present setting have a common interest to agree, is characterized in section 4. Moreover, to illustrate a potential application of our model, it is shown that a buyer might prefer to contract with a seller who is known to have smaller success probabilities than an alternative seller (both given high and given low effort). We will also briefly discuss renegotiation in our context. Finally, the cases in which depending on the realized quality it may be ex post efficient not to trade are analyzed in section 5. Some concluding remarks follow in section 6 .

\section{The model}

Consider a (potential) seller and a (potential) buyer, who meet at some initial date 0, when they are still symmetrically informed. Both parties are risk-neutral and there are no (binding) wealth constraints. The seller

valuation, Maskin and Moore (1999) have shown that contracting is useless. This result has also been further generalized by Che and Hausch (1999). See Lyon and Rasmusen (2004) for a discussion of their assumptions regarding renegotiation.

${ }^{11}$ For surveys of this literature, see Schwartz (1998), Tirole (1999), and Schmitz (2001).

${ }^{12}$ See also Schmitz $(2008 \mathrm{a}, \mathrm{b})$. Taking private information into account brings the property rights approach closer to transaction cost economics; indeed, Williamson (2000, 2002) has criticized the property rights theory since it typically neglects ex post inefficiencies. Note that ex post inefficiencies cannot only be explained by private information, but also by behavioral effects (see Hart and Moore, 2008, and Hart, 2008, 2009). 
and the buyer can write a contract regarding the terms of trade of an indivisible good that can be produced at date 1 and exchanged at date 2 . In accordance with the traditional principal-agent (or mechanism design) approach, it is assumed throughout that the parties can write a complete contract in the sense of Tirole (1999). In particular, they can rule out future renegotiation. ${ }^{13}$ Note that this assumption can only strengthen our impossibility result.

At date 1, the seller decides how much effort to exert while producing the good (i.e., she can make a relationship-specific investment). She can either shirk $\left(e=e_{l}\right)$ or work hard $\left(e=e_{h}\right)$, where $0 \leq e_{l}<e_{h}<1$. Her disutility of effort is given by $c(e)$, where $c\left(e_{l}\right)=0$ and $c\left(e_{h}\right)=c>0 .{ }^{14}$ The quality of the good produced is determined by the seller's effort level and the state of the world, which is realized at date 1.5. Specifically, assume that the quality is high $(q=h)$ with probability $e$ and low $(q=l)$ with probability $1-e$. At date 2 , trade can occur and payments can be made according to the contract.

The buyer's value from receiving the good is denoted by $v_{q}$, where $0<$ $v_{l}<v_{h}$. If trade does not occur, the seller consumes the good. Her value is denoted by $w_{q}$, where $0<w_{l}<w_{h}$.

Assumption 1. Trade is always ex post efficient $\left(w_{l}<v_{l}\right.$ and $\left.w_{h}<v_{h}\right)$.

In other words, while both parties prefer to consume a good that has a high quality, it is common knowledge that the buyer's value is always larger than the seller's value. It turns out that this is the most interesting case (the other conceivable parameter constellations will be analyzed in section $5)$.

Let $x \in[0,1]$ denote the level of trade and let $t^{B}$ and $t^{S}$ denote the payments that the buyer and the seller receive, respectively. ${ }^{15}$ While all

\footnotetext{
${ }^{13}$ See section 4.2 for a more detailed discussion regarding renegotiation.

${ }^{14}$ The assumption $c\left(e_{l}\right)=0$ is made for expositional simplicity only. It is straightforward to extend the model to the case in which there are additional costs $c_{l}>0$ that are always incurred (i.e., even if effort is low).

${ }^{15}$ In accordance with Myerson and Satterthwaite (1983) and many subsequent papers, the good is assumed to be indivisible, so the trade level is a probability. Alternatively, one could imagine that the good is divisible and there is a capacity constraint of 1 .
} 
of our results would go through if we simply assumed $t^{B} \equiv-t^{S}$, we allow money burning and the inclusion of third parties that can break the budget; i.e., we assume only that $E\left[t^{B}+t^{S}\right] \leq 0$ must hold in equilibrium. Notice that this only strengthens our impossibility result. ${ }^{16}$

The payoffs of the buyer and the seller are given by

$$
\begin{aligned}
& u^{B}=t^{B}+x v_{q}, \\
& u^{S}=t^{S}+(1-x) w_{q}-c(e) .
\end{aligned}
$$

If the parties do not agree on a contract, their reservation utilities are given by zero. ${ }^{17}$ Recall that at date 0 , the parties are still symmetrically informed and there are no wealth constraints. Hence, in accordance with the Coase Theorem, they always write a contract that maximizes their expected total surplus. They can divide the surplus with the help of appropriate lump sum components of the payments (or, equivalently, additional up-front payments).

The first-best benchmark. If effort were verifiable, the parties would write a contract according to which the good is always traded and the seller must choose

$$
e^{F B} \in \arg \max e v_{h}+(1-e) v_{l}-c(e) .
$$

Depending on the parties' bargaining powers, the buyer would pay to the seller a lump sum amount $t^{S}=-t^{B} \in\left[c\left(e^{F B}\right), e^{F B} v_{h}+\left(1-e^{F B}\right) v_{l}\right]$, so that

\footnotetext{
${ }^{16}$ Recall that in the literature there are impossibility results that do not hold if one allows money burning or budgets that are unbalanced ex post (or off-equilibrium) only. Note that if the parties can commit to ex post inefficient trade (which is a standard assumption in adverse selection models), it is not obvious why commitment to inefficient money burning should be ruled out a priori. Similarly, if the courts enforce only publicly registered contracts, collusive side agreements are not enforceable, hence the inclusion of third parties as budget breakers should not be ruled out a priori.

${ }^{17}$ This assumption is justified if the buyer has to contribute a relationship-specific investment (which for simplicity causes no costs), so that the seller cannot produce the good in the absence of the buyer. For example, the buyer might own a blueprint for the (innovative) good. Notice that only the intervals in which the transfer payments must lie would change if we assumed instead that the seller could produce the good without the buyer's consent, so that the seller's reservation utility would be $\max \left\{e w_{h}+(1-\right.$ $\left.e) w_{l}-c(e)\right\}$.
} 
voluntary participation by both parties is ensured. Note that if

$$
v_{h}-v_{l}>\frac{c}{e_{h}-e_{l}}
$$

then $e^{F B}=e_{h}$. In other words, high instead of low effort should be exerted if the costs of doing so, $c$, are smaller than the increase in probability that the quality will be high, $e_{h}-e_{l}$, times the buyer's additional willingnessto-pay when the quality is high, $v_{h}-v_{l}$.

It should be emphasized that even when effort is a hidden action, the first best would still be attained if quality were verifiable. In this case, the parties would write a contract which says that the good is always traded and $t^{S}=-t^{B}=v_{q}$-const, where const $\in\left[0, e^{F B} v_{h}+\left(1-e^{F B}\right) v_{l}-c\left(e^{F B}\right)\right]$. Thus, the seller's expected payoff at date 1 would be $e v_{h}+(1-e) v_{l}-c(e)-$ const and as a residual claimant she would choose the first-best effort level.

To summarize, if there were only hidden information or only hidden action, then the parties would always write a contract that implements the first best. In contrast, we will see in the following section that the simultaneous presence of hidden action and hidden information leads to an impossibility result.

\section{A new and simple impossibility result}

In what follows, the effort choice $e$ is a hidden action and (as is the case in the standard lemons model of Akerlof, 1970) the quality $q$ will be private information of the seller. In accordance with the traditional complete contracting (or mechanism design) approach, it is assumed throughout that the courts enforce contracts specifying trade and payment rules $\left(x, t^{B}, t^{S}\right)$ which are based on verifiable variables (including messages sent by the parties).

Due to the revelation principle (cf. Myerson, 1982), the analysis can be confined to direct revelation mechanisms. ${ }^{18}$ Such a mechanism prescribes

\footnotetext{
${ }^{18}$ It should be noted that it is implicitly assumed that the actual quality will never be observable by the buyer (or at least not in a timeframe in which contractual payments could still be prescribed). This assumption is implicitly made in almost all models with common (i.e., interdependent) values (including Akerlof's lemons market), even though
} 
a trade level $x(\tilde{q})$ and payments $t^{B}(\tilde{q}), t^{S}(\tilde{q})$ contingent on the seller's announcement of the quality, $\tilde{q}$. For notational simplicity, let $\left(x_{l}, t_{l}^{B}, t_{l}^{S}\right)$ and $\left(x_{h}, t_{h}^{B}, t_{h}^{S}\right)$ denote the alternatives between which the seller can choose by announcing $\tilde{q}=q_{l}$ or $\tilde{q}=q_{h}$. The incentive compatibility conditions which make truth-telling an optimal strategy for the seller are

$$
\begin{aligned}
t_{h}^{S}+\left(1-x_{h}\right) w_{h} & \geq t_{l}^{S}+\left(1-x_{l}\right) w_{h}, \\
t_{l}^{S}+\left(1-x_{l}\right) w_{l} & \geq t_{h}^{S}+\left(1-x_{h}\right) w_{l} .
\end{aligned}
$$

The seller is willing to choose the high level of effort whenever

$$
\begin{aligned}
& e_{h}\left(t_{h}^{S}+\left(1-x_{h}\right) w_{h}\right)+\left(1-e_{h}\right)\left(t_{l}^{S}+\left(1-x_{l}\right) w_{l}\right)-c \\
\geq & e_{l}\left(t_{h}^{S}+\left(1-x_{h}\right) w_{h}\right)+\left(1-e_{l}\right)\left(t_{l}^{S}+\left(1-x_{l}\right) w_{l}\right),
\end{aligned}
$$

which is equivalent to

$$
t_{h}^{S}-t_{l}^{S}+\left(1-x_{h}\right) w_{h}-\left(1-x_{l}\right) w_{l} \geq \frac{c}{e_{h}-e_{l}} .
$$

If the effort choice $e$ is to be implemented, the buyer's and the seller's participation constraints read

$$
\begin{gathered}
e\left(t_{h}^{B}+x_{h} v_{h}\right)+(1-e)\left(t_{l}^{B}+x_{l} v_{l}\right) \geq 0 \\
e\left(t_{h}^{S}+\left(1-x_{h}\right) w_{h}\right)+(1-e)\left(t_{l}^{S}+\left(1-x_{l}\right) w_{l}\right)-c(e) \geq 0
\end{gathered}
$$

and ex ante budget balance requires that

$$
e\left(t_{h}^{B}+t_{h}^{S}\right)+(1-e)\left(t_{l}^{B}+t_{l}^{S}\right) \leq 0 .
$$

It is easy to see that the first best will be achieved if $e^{F B}=e_{l}$. However, if high effort is first-best, then an impossibility result holds.

Proposition 1 (a) If $v_{h}-v_{l} \leq c /\left(e_{h}-e_{l}\right)$, then the parties will implement the first best.

(b) If $v_{h}-v_{l}>c /\left(e_{h}-e_{l}\right)$, so that $e^{F B}=e_{h}$, then it is impossible to achieve the first best.

only some authors mention it explicitly; see e.g. Myerson (1985, p. 131) or Samuelson (1984, p. 997). If this assumption is not made, then the mechanism of Mezzetti (2004) could be used, in which the buyer reports the quality after he has learned it. See Jehiel and Moldovanu (2006) for a criticism of this kind of mechanism. 
Proof. (a) If $v_{h}-v_{l} \leq c /\left(e_{h}-e_{l}\right)$, then the parties agree on a contract $x_{l}=x_{h}=1$ (so that ex post efficiency is achieved) and $t_{l}^{S}=t_{h}^{S}=-t_{l}^{B}=$ $-t_{h}^{B} \in\left[0, e_{l} v_{h}+\left(1-e_{l}\right) v_{l}\right]$. Hence, participation by both parties is ensured and the seller chooses $e=e_{l}$, which maximizes the expected total surplus.

(b) In the first-best solution, $x_{l}=x_{h}=1$. Hence, the incentive compatibility constraint $(I C)$ that ensures high effort reads $t_{h}^{S}-t_{l}^{S} \geq c /\left(e_{h}-e_{l}\right)$, while the truth-telling constraint for the low-quality case $\left(T T_{l}\right)$ reads $t_{l}^{S} \geq$ $t_{h}^{S}$. It is impossible to satisfy both constraints simultaneously.

Intuitively, given that the good will always be traded, the seller will exert high effort only if she gets a sufficiently larger payment when the quality is high. Yet, the seller will truthfully reveal a low quality only if she does not get a lower payment when the quality is low. Thus, it is impossible to simultaneously solve the hidden action and the hidden information problem. Notice that (in contrast to Schmitz, 2002b) the impossibility result does not rely on an assumption according to which there is no third party who could act as a budget breaker.

\section{The second best}

As has already been pointed out, at date 0 the (symmetrically informed) parties will always agree on a contract that maximizes their expected total surplus. When the first best cannot be achieved, we thus have to look for the second best, which maximizes the parties' expected total surplus subject to all incentive constraints. The parties implement the second best regardless of their bargaining powers. Hence, in contrast to adverse selection models, we do not have to specify who offers the contract, which here affects only the division of the surplus.

Let a threshold cost level be defined by

$$
\hat{c}=\frac{\left(e_{h}-e_{l}\right)^{2}\left(v_{h}-v_{l}\right)\left(w_{h}-w_{l}\right)}{e_{h}\left(v_{h}-w_{l}\right)-e_{l}\left(w_{h}-w_{l}\right)} .
$$

The second best can then be characterized as follows.

Proposition 2 Consider the case $v_{h}-v_{l}>c /\left(e_{h}-e_{l}\right)$, so that $e^{F B}=e_{h}$ and the first best cannot be achieved. In the second-best solution, the parties implement the following effort and trade levels. 
- If $c \geq \hat{c}$, then low effort is implemented, $e^{S B}=e_{l}$, while ex post efficiency is achieved, $x_{l}^{S B}=x_{h}^{S B}=1$.

- If $c<\hat{c}$, then high effort is implemented, $e^{S B}=e_{h}$. Moreover, $x_{l}^{S B}=$ 1 and

$$
x_{h}^{S B}=1-\frac{c}{\left(e_{h}-e_{l}\right)\left(w_{h}-w_{l}\right)},
$$

so that there is a downward distortion of the trade level if and only if the quality is high.

Proof. The proof proceeds in three steps.

(i) Assume first that the parties want to implement $e=e_{h}$. At date 0 , the parties design a contract $\left(x_{l}, x_{h}, t_{l}^{S}, t_{h}^{S}, t_{l}^{B}, t_{h}^{B}\right)$ in order to maximize their expected total surplus

$e_{h}\left[w_{h}+x_{h}\left(v_{h}-w_{h}\right)+t_{h}^{B}+t_{h}^{S}\right]+\left(1-e_{h}\right)\left[w_{l}+x_{l}\left(v_{l}-w_{l}\right)+t_{l}^{B}+t_{l}^{S}\right]-c$ subject to $\left(T T_{h}\right),\left(T T_{l}\right),(I C),\left(P C^{B}\right),\left(P C^{S}\right),(B B)$, and the constraints that $x_{h}$ and $x_{l}$ must lie in the unit interval. The truth-telling constraints can be rewritten as

$$
\begin{aligned}
& t_{h}^{S}-t_{l}^{S} \geq\left(x_{h}-x_{l}\right) w_{h}, \\
& t_{h}^{S}-t_{l}^{S} \leq\left(x_{h}-x_{l}\right) w_{l},
\end{aligned}
$$

which implies $x_{h} \leq x_{l}$. Note that $(B B)$ must be binding, because otherwise $t_{l}^{B}$ and $t_{h}^{B}$ could be increased without violating any side constraints.

Let us first ignore the constraints $\left(T T_{h}\right),\left(P C^{B}\right),\left(P C^{S}\right)$, and $0 \leq x_{h} \leq$ 1. The simplified problem is thus to choose $\left(x_{l}, x_{h}, t_{l}^{S}, t_{h}^{S}\right)$ in order to maximize

$$
e_{h}\left[w_{h}+x_{h}\left(v_{h}-w_{h}\right)\right]+\left(1-e_{h}\right)\left[w_{l}+x_{l}\left(v_{l}-w_{l}\right)\right]-c
$$

subject to

$$
\begin{gathered}
t_{h}^{S}-t_{l}^{S} \leq\left(x_{h}-x_{l}\right) w_{l}, \\
t_{h}^{S}-t_{l}^{S} \geq \frac{c}{e_{h}-e_{l}}-\left(1-x_{h}\right) w_{h}+\left(1-x_{l}\right) w_{l},
\end{gathered}
$$

and $0 \leq x_{l} \leq 1$. Note that $t_{h}^{S}$ and $t_{l}^{S}$ do not appear in the objective function, so we can replace $\left(T T_{l}\right)$ and $(I C)$ by

$$
\frac{c}{e_{h}-e_{l}}-\left(1-x_{h}\right) w_{h}+w_{l} \leq x_{h} w_{l} \text {. }
$$


Hence, if $c>\left(e_{h}-e_{l}\right)\left(1-x_{h}\right)\left(w_{h}-w_{l}\right)$, then $e=e_{h}$ cannot be implemented. It follows that if $c>\left(e_{h}-e_{l}\right)\left(w_{h}-w_{l}\right)$, so that even with $x_{h}=0$ it is impossible to implement high effort, then $e^{S B}=e_{l}$ must hold.

Consider now the remaining case $c \leq\left(e_{h}-e_{l}\right)\left(w_{h}-w_{l}\right)$. High effort can then be implemented if $x_{h}$ is made sufficiently small. Notice that the parties want to set $x_{h}$ as large as possible, because $v_{h}>w_{h}$. The largest value of $x_{h}$ such that the seller is still willing to exert high effort is given by $c=\left(e_{h}-e_{l}\right)\left(1-x_{h}\right)\left(w_{h}-w_{l}\right)$, which can be rewritten as

$$
x_{h}=1-\frac{c}{\left(e_{h}-e_{l}\right)\left(w_{h}-w_{l}\right)} .
$$

Moreover, $x_{l}=1$ must hold in the optimal solution, because $v_{l}>w_{l}$.

The transfer payments can be chosen such that $t_{h}^{B}=-t_{h}^{S}, t_{l}^{B}=-t_{l}^{S}$,

$$
t_{h}^{S}=t_{l}^{S}-\frac{c}{\left(e_{h}-e_{l}\right)\left(w_{h}-w_{l}\right)} w_{l}
$$

and

$$
t_{l}^{S} \in\left[-\frac{e_{l}}{e_{h}-e_{l}} c, e_{h} v_{h}+\left(1-e_{h}\right) v_{l}-\frac{v_{h}-w_{l}}{\left(e_{h}-e_{l}\right)\left(w_{h}-w_{l}\right)} e_{h} c\right]
$$

It is straightforward to check that then all of the omitted constraints $\left(T T_{h}\right)$, $\left(P C^{B}\right),\left(P C^{S}\right)$, and $0 \leq x_{h} \leq 1$ are satisfied, so that in fact we have found the optimal solution to the original problem.

(ii) Assume now that the parties implement $e=e_{l}$. It is easy to see that it is optimal to set $x_{l}=x_{h}=1$, and all constraints are satisfied for $e=e_{l}$ if $t_{h}^{S}=t_{l}^{S}=-t_{h}^{B}=-t_{l}^{B} \in\left[0, e_{l} v_{h}+\left(1-e_{l}\right) v_{l}\right]$.

(iii) When the parties implement $e=e_{l}$, the expected total surplus is

$$
e_{l} v_{h}+\left(1-e_{l}\right) v_{l}
$$

When they implement $e=e_{h}$, which is possible only if $c \leq\left(e_{h}-e_{l}\right)\left(w_{h}-w_{l}\right)$, then the expected total surplus is

$$
e_{h} v_{h}+\left(1-e_{h}\right) v_{l}-c-\frac{v_{h}-w_{h}}{\left(e_{h}-e_{l}\right)\left(w_{h}-w_{l}\right)} e_{h} c
$$

where the last term is the loss due to the distortion $x_{h}<1$. Hence, high effort leads to a larger expected total surplus if $c<\hat{c}$. Note that $\hat{c} \leq$ $\left(e_{h}-e_{l}\right)\left(w_{h}-w_{l}\right)$. The proposition thus follows immediately. 
According to Proposition 2, there are two cases. First, if the effort costs are large, the parties implement low effort and achieve ex post efficiency. Second, if the effort costs are sufficiently small, they implement high effort. However, this is only possible if the trade level is distorted downwards whenever the quality (and hence the seller's opportunity cost) is high. In this case, the seller is willing to invest high effort in the production of the good, because she directly benefits from a high quality level when the good is not exchanged.

\subsection{An application: Why a principal might hire an inexperienced agent}

Let us now briefly consider an interesting implication of the second-best solution. Assume that the buyer (who is the principal) can contract with one of two sellers (i.e., agents), $A$ or $B$. Seller $A$ is a more experienced producer than seller $B$, so that even if she shirks, seller $A$ will produce a high-quality good with probability $e_{l}^{A}$, which is larger than seller $B$ 's probability of producing a high-quality good when she shirks, $e_{l}^{B}$. Similarly, seller $A$ may also produce high quality with a larger probability than seller $B$ when the effort level is high. Apart from that, the sellers are identical. At first sight, one might suspect that the buyer should always prefer to contract with the more experienced seller $A$. Yet, this is not the case.

Corollary 1 Assume that the buyer can contract with either seller $A$ or seller $B$, where $e_{l}^{A}>e_{l}^{B}$ and $e_{h}^{A}>e_{h}^{B}$. The sellers are identical otherwise. If $e_{h}^{A}-e_{l}^{A}<e_{h}^{B}-e_{l}^{B}$, then the buyer may prefer to contract with seller $B$.

In order to see this, note that when high effort is implemented, the loss due to the distortion (see the proof of Proposition 2) is given by $\left(v_{h}-\right.$ $\left.w_{h}\right) e_{h} c /\left(e_{h}-e_{l}\right)\left(w_{h}-w_{l}\right)$, which is increasing in $e_{l}$. Hence, if $e_{h}^{A}=e_{h}^{B}$, then the expected total surplus is larger when the buyer contracts with the unexperienced seller $B$. By continuity, there are also cases in which this remains true even when in addition $e_{h}^{A}>e_{h}^{B} \cdot{ }^{19}$ Intuitively, if $e_{h}^{A}-e_{l}^{A}<e_{h}^{B}-$

\footnotetext{
${ }^{19}$ For example, let $v_{h}=10, v_{l}=6, w_{h}=4, w_{l}=2, c=.1, e_{h}^{A}=.9, e_{h}^{B}=.8, e_{l}^{A}=.6$, $e_{l}^{B}=.2$. It is straightforward to verify that the parties will implement high effort and
} 
$e_{l}^{B}$, then it is relatively cheaper to motivate agent $B$ to exert high instead of low effort, and the smaller agency costs of agent $B$ can overcompensate the fact that the levels of agent $A$ 's success probabilities are larger. Notice that the Corollary holds even though complete contracts can be written; i.e., in particular it does not rely on an assumption according to which renegotiation cannot be ruled out.

\subsection{A remark on renegotiation}

In the contract-theoretic literature, there is a vital debate about whether or not one should assume that renegotiation can be ruled out. In the main part of the present paper, we follow the mechanism design literature on (im)possibility results in adverse selection frameworks (in the tradition of Myerson and Satterthwaite, 1983) as well as Rogerson's (1992) seminal work on contractual solutions to the hold-up problem, in which it is assumed that renegotiation can be excluded. Indeed, in a complete contracting world, all contractual clauses based on verifiable events should be enforceable, including clauses that rule out renegotiation. ${ }^{20}$ Specifically, Maskin and Tirole (1999) criticize that in the recent incomplete contracting literature, the assumption that renegotiation cannot be prevented is motivated by considerations that lie outside the existing models. In contrast, Hart and Moore (1999) argue that in practice it may be impossible to enforce contractual clauses that rule out renegotiation. ${ }^{21}$

In an otherwise complete contracting world, the impossibility to rule out renegotiation can only impose additional constraints and hence reduce the expected total surplus that the parties can generate. Since the result of future renegotiation can always be included in the initial contract, the

that the expected total surplus is 8.6 if the buyer contracts with the experienced seller $A$, while the expected total surplus is 8.7 if the buyer contracts with the unexperienced seller $B$.

${ }^{20}$ As has been pointed out by Maskin and Tirole (1999, p. 99), the parties could register their contract publicly, i.e. the contract is lodged in court (Tirole, 1999, p. 746).

${ }^{21}$ See also the dialogue between a "complete contract theorist" and an "incomplete contract theorist" in Tirole (1999, section 2.5). For a law and economics perspective on this discussion, see Schmitz (2005) and Davis (2006). 
impossibility to exclude renegotiation means that the initial contract has to satisfy additional renegotiation-proofness constraints. Since in our framework it is common knowledge that it is always ex post efficient to trade, a contract is renegotiation-proof if trade always takes place, $x=1$. However, if we insist on ex post efficiency, we already know from the analysis in section 3 that it is impossible to induce high effort, so that only the expected total surplus $e_{l} v_{h}+\left(1-e_{l}\right) v_{l}$ can be attained. ${ }^{22}$

\section{The cases in which it may be ex post effi- cient not to trade}

So far, we have focused on the case in which it is always ex post efficient to trade $\left(v_{h}>w_{h}\right.$ and $\left.v_{l}>w_{l}\right)$. While this might be the most interesting case, other parameter constellations are also conceivable. In this section, we return to our original model in which the parties can write complete contracts and commit not to renegotiate, but now Assumption 1 no longer holds. Of course, if $v_{h}<w_{h}$ and $v_{l}<w_{l}$, then the first best is trivial to achieve, because trade is never ex post efficient and thus the seller obviously chooses the first-best effort level. Let us now consider the remaining cases, in which the ex post efficient trade level depends upon the realized quality. ${ }^{23}$

Proposition 3 (a) If $v_{h}<w_{h}$ and $v_{l}>w_{l}$, so that it is ex post efficient to trade whenever the quality is low, the parties achieve the first best.

(b) If $v_{h}>w_{h}$ and $v_{l}<w_{l}$, so that it is ex post efficient to trade whenever the quality is high, it is impossible to achieve the first best.

\footnotetext{
${ }^{22}$ Note that alternatively one might assume a specific bargaining game to be played if the initial contract does not lead to ex post efficiency (e.g., one party might make a "takeit-or-leave-it" offer). But then it is unclear why an inefficient outcome of this bargaining game (e.g., "leave it") cannot be renegotiated. See also Rubinstein and Wolinsky (1992), who argue in their Proposition 1 that hardly anything can be implemented if one insists on renegotiation-proofness of the renegotiation game.

${ }^{23}$ It is straightforward to extend the analysis to the knife-edge cases $v_{h}=w_{h}$ and/or $v_{l}=w_{l}$, where the levels of $x_{l}$ and/or $x_{h}$ are irrelevant for the total surplus. For instance, if $v_{h}=w_{h}$ and $v_{l}=w_{l}$, the first best can obviously be achieved (by not trading at all or by trading whenever the quality is low).
} 
Proof. (a) If $v_{h}<w_{h}$ and $v_{l}>w_{l}$, ex post efficiency requires $x_{h}^{F B}=$ $0, x_{l}^{F B}=1$. It is ex ante efficient to choose the high level of effort if $e_{h} w_{h}+\left(1-e_{h}\right) v_{l}-c \geq e_{l} w_{h}+\left(1-e_{l}\right) v_{l}$, which can be rewritten as $\left(e_{h}-\right.$ $\left.e_{l}\right)\left(w_{h}-v_{l}\right) \geq c$. When the contract prescribes the ex post efficient trade levels, the seller's $(I C)$ constraint reads $\left(e_{h}-e_{l}\right)\left(t_{h}^{S}-t_{l}^{S}+w_{h}\right) \geq c$. Hence, the seller makes the desired effort decision if $t_{h}^{S}=t_{l}^{S}-v_{l}$. In this case, the truth-telling constraints (which require $-w_{h} \leq t_{h}^{S}-t_{l}^{S} \leq-w_{l}$ ) are also satisfied. Furthermore, the parties can set $t_{h}^{B}=-t_{h}^{S}, t_{l}^{B}=-t_{l}^{S}$, and $t_{l}^{S} \in\left[c\left(e^{F B}\right)-e^{F B}\left(w_{h}-v_{l}\right), v_{l}\right]$, so that budget balance and both parties' participation constraints are satisfied.

(b) If $v_{h}>w_{h}$ and $v_{l}<w_{l}$, then $x_{h}^{F B}=1, x_{l}^{F B}=0$. It is impossible to implement ex post efficient trade, because the truth-telling constraints imply $x_{h} \leq x_{l}$ (see the proof of Proposition 2).

Intuitively, if it is ex post efficient to trade whenever the quality is low, there is no trade-off between ex ante investment incentives and ex post efficiency. The seller can be given the correct incentives to invest qualityimproving effort into the production of the good, because she consumes the good herself whenever the quality is high.

If it is ex post efficient to trade whenever the quality is high, an inefficiency result holds. It should be emphasized that, in contrast to Proposition $1 \mathrm{~b}$, the impossibility result in Proposition $3 \mathrm{~b}$ is not novel. In the case studied in Proposition 3b, it is simply not possible to implement ex post efficient trade (regardless of whether or not effort is hidden). ${ }^{24}$ While the impossibility result thus is less interesting, we still have to characterize the second-best solution. For this purpose, define a threshold cost level by

$$
\tilde{c}=\left(e_{h}-e_{l}\right)\left(w_{h}-w_{l}\right) \min \left\{\frac{\left(e_{h}-e_{l}\right)\left(v_{h}-v_{l}\right)}{e_{h} v_{h}+\left(1-e_{h}\right) v_{l}-e_{l} w_{h}-\left(1-e_{l}\right) w_{l}}, 1\right\} .
$$

Proposition 4 Consider the case $v_{h}>w_{h}$ and $v_{l}<w_{l}$, so that the first best cannot be achieved. The second-best solution can be characterized as follows.

\footnotetext{
${ }^{24}$ It is well-known that ex post efficiency is unattainable when the monotonicity constraint implied by incentive compatibility is violated by the ex post efficient trading rule; see e.g. Laffont and Martimort (2002, p. 53).
} 
- If $c \geq \tilde{c}$, the parties implement low effort, $e^{S B}=e_{l}$. Moreover, $x_{l}^{S B}=$ $x_{h}^{S B}=1$ if $e_{l}\left(v_{h}-w_{h}\right)+\left(1-e_{l}\right)\left(v_{l}-w_{l}\right)>0$, and $x_{l}^{S B}=x_{h}^{S B}=0$ otherwise.

- If $c<\tilde{c}$, the parties implement high effort, $e^{S B}=e_{h}$. Moreover, $x_{l}^{S B}=x_{h}^{S B}=0$ if $e_{h}\left(v_{h}-w_{h}\right)+\left(1-e_{h}\right)\left(v_{l}-w_{l}\right) \leq 0$, and

$$
x_{l}^{S B}=x_{h}^{S B}=1-\frac{c}{\left(e_{h}-e_{l}\right)\left(w_{h}-w_{l}\right)}
$$

otherwise.

Proof. We proceed again in three steps.

(i) In analogy to the proof of Proposition 2, it is again true that $e^{S B}=$ $e_{l}$ must hold if $c>\left(e_{h}-e_{l}\right)\left(w_{h}-w_{l}\right)$. Otherwise, high effort can be implemented. Recall that the truth-telling constraints imply $x_{h} \leq x_{l}$. Since $v_{l}<w_{l}$, the parties will now make $x_{l}$ as small as possible, so that $x_{l}=$ $x_{h}=x$. Their expected total surplus when they implement high effort is $e_{h} w_{h}+\left(1-e_{h}\right) w_{l}+x\left[e_{h}\left(v_{h}-w_{h}\right)+\left(1-e_{h}\right)\left(v_{l}-w_{l}\right)\right]-c$. Hence, when they implement high effort, it is optimal for them to choose $x=1-c /\left(e_{h}-\right.$ $\left.e_{l}\right)\left(w_{h}-w_{l}\right)$ if $e_{h}\left(v_{h}-w_{h}\right)+\left(1-e_{h}\right)\left(v_{l}-w_{l}\right)>0$, and $x=0$ otherwise. Then all constraints are satisfied if $t_{h}^{S}=t_{l}^{S}=-t_{h}^{B}=-t_{l}^{B} \in\left[c-(1-x)\left(e_{h} w_{h}+\left(1-e_{h}\right) w_{l}\right), x\left(e_{h} v_{h}+\left(1-e_{h}\right) v_{l}\right)\right]$.

(ii) When the parties implement low effort, they will also set $x_{l}=x_{h}=$ $x$. It is optimal for them to set $x=1$ if $e_{l}\left(v_{h}-w_{h}\right)+\left(1-e_{l}\right)\left(v_{l}-w_{l}\right)>0$ and $x=\max \left\{0,1-c /\left(e_{h}-e_{l}\right)\left(w_{h}-w_{l}\right)\right\}$ otherwise. Then all constraints are satisfied if

$$
t_{h}^{S}=t_{l}^{S}=-t_{h}^{B}=-t_{l}^{B} \in\left[(x-1)\left(e_{l} w_{h}+\left(1-e_{l}\right) w_{l}\right), x\left(e_{l} v_{h}+\left(1-e_{l}\right) v_{l}\right)\right] .
$$

(iii) If $c>\left(e_{h}-e_{l}\right)\left(w_{h}-w_{l}\right)$, the parties implement low effort and the expected total surplus is

$$
\max \left\{e_{l} v_{h}+\left(1-e_{l}\right) v_{l}, e_{l} w_{h}+\left(1-e_{l}\right) w_{l}\right\}
$$

Consider now the case $c \leq\left(e_{h}-e_{l}\right)\left(w_{h}-w_{l}\right)$. If the parties implement $e=e_{l}$, the expected total surplus is

$$
\max \left\{e_{l} v_{h}+\left(1-e_{l}\right) v_{l}, e_{l} v_{h}+\left(1-e_{l}\right) v_{l}-\frac{e_{l}\left(v_{h}-w_{h}\right)+\left(1-e_{l}\right)\left(v_{l}-w_{l}\right)}{\left(e_{h}-e_{l}\right)\left(w_{h}-w_{l}\right)} c\right\} .
$$


If they implement $e=e_{h}$, the expected total surplus is $\max \left\{e_{h} v_{h}+\left(1-e_{h}\right) v_{l}-\frac{e_{h}\left(v_{h}-w_{h}\right)+\left(1-e_{h}\right)\left(v_{l}-w_{l}\right)}{\left(e_{h}-e_{l}\right)\left(w_{h}-w_{l}\right)} c, e_{h} w_{h}+\left(1-e_{h}\right) w_{l}\right\}-c$.

It is thus straightforward to show that the proposition is true.

There are again two cases. If the effort costs are large, low effort is implemented, while the trade level now does not depend on the quality. Either the good is always exchanged or it is not traded at all. If the effort costs are small, high effort is implemented. The trade level again does not depend on the quality. The good is either kept by the seller or the trade level is sufficiently small such that the seller can directly benefit from high quality and she thus has an incentive to invest effort in the production of the good.

\section{Concluding remarks}

Many relevant economic phenomena have been explained in the contracttheoretic literature by distortions obtained in adverse selection models that rely on precontractual private information. ${ }^{25}$ However, there are circumstances under which it might be doubtful whether this is the most relevant source of distortions. For instance, in a long-term relationship between an owner and a manager, precontractual private information about the manager's effort costs (as assumed in adverse selection models) may be less relevant than postcontractual asymmetric information.

In the present paper, it has been illustrated that distortions similar to the ones known from adverse selection models can also be obtained in models without precontractual private information, when hidden action and hidden information are combined. If common values are involved, the distortions are robust in the sense that even the introduction of third parties cannot avoid them. Moreover, the model is simple and it has the advantage that the second-best analysis is relevant, regardless of the bargaining protocol. Hence, it might be desirable to use the current model as a building

\footnotetext{
${ }^{25}$ See Laffont and Martimort (2002) and Bolton and Dewatripont (2005) for recent and comprehensive textbook expositions.
} 
block in more applied work in order to analyze some of the phenomena that so far have been addressed only in models with precontractual private information. In particular, the hold-up problem plays a prominent role in the theory of the firm. Introducing postcontractual asymmetric information about quality into models of the property rights approach to the theory of the firm might be a fruitful avenue for future research.

\section{Acknowledgments}

I would like to thank Eva Hoppe for many very valuable and inspiring discussions. Moreover, I am grateful to Jin Li, Jörg Oechssler, Andreas Roider, Wendelin Schnedler, seminar participants in Bonn, Cologne, Heidelberg, and Mannheim, participants of the 7th International Industrial Organization Conference (Boston, 2009), and an anonymous referee for making helpful comments and suggestions. 


\section{References}

Akerlof, G.A., 1970. The market for lemons: Quality uncertainty and the market mechanism. Quarterly Journal of Economics 84, 488-500.

Annen, K., 2009. Efficiency out of disorder: Contested ownership in incomplete contracts. Rand Journal of Economics 40, 597-610.

Arrow, K.J., 1979. The property rights doctrine and demand revelation under incomplete information. In: Boskin, M.J. (Ed.), Economics and Human Welfare - Essays in Honor of Tibor Scitovsky. Academic Press, New York, pp. 23-39.

d'Aspremont, C., Gérard-Varet, L.-A., 1979. Incentives and incomplete information. Journal of Public Economics 11, 25-45.

Bester, H., 2009. Investments and the holdup problem in a matching market. SFB/TR 15 Discussion Paper No. 263.

Bolton, P., Dewatripont, M., 2005. Contract Theory. Cambridge: MIT Press.

Che, Y.-K., Hausch, D.B., 1999. Cooperative investments and the value of contracting. American Economic Review 89, 125-147.

Cramton, P., Gibbons, R., Klemperer, P., 1987. Dissolving a partnership efficiently. Econometrica 55, 615-632.

Crémer, J., Riordan, M.H., 1985. A sequential solution to the public goods problem. Econometrica 53, 77-84.

Davis, K.E., 2006. The demand for immutable contracts: Another look at the law and economics of contract modifications. New York University Law Review 81, 487-549.

Farrell, J., Gibbons, R., 1995. Cheap talk about specific investments. Journal of Law, Economics, and Organization 11, 313-334.

Fudenberg, D., Tirole, J., 1991. Game Theory. Cambridge: MIT Press.

Froeb, L., Ganglmair, B., 2009. Innovation, patent hold-up, and equilibrium effects of RAND commitments. Discussion Paper. 
Grossman, S.J., Hart, O.D., 1986. The costs and benefits of ownership: A theory of vertical and lateral integration. Journal of Political Economy 94, 691-719.

Grüner, H.-P., 2008. Public goods, participation constraints, and democracy: A possibility theorem. Discussion Paper.

Guriev, S., 2003. Incomplete contracts with cross-investments. Contributions to Theoretical Economics 3, Article 5.

Hart, O.D., 1995. Firms, Contracts and Financial Structure. Oxford: Clarendon Press.

Hart, O., 2008. Reference points and the theory of the firm. Economica 75, 404-411.

Hart, O., 2009. Hold-up, asset ownership, and reference points. Quarterly Journal of Economics 124, 267-300.

Hart, O., Moore, J., 1988. Incomplete contracts and renegotiation. Econometrica $56,755-785$.

Hart, O.D., Moore, J., 1990. Property rights and the nature of the firm. Journal of Political Economy 98, 1119-1158.

Hart, O., Moore, J., 1999. Foundations of incomplete contracts. Review of Economic Studies 66, 115-138.

Hart, O., Moore, J., 2008. Contracts as reference points. Quarterly Journal of Economics 123, 1-48.

Hart, O., Shleifer, A., Vishny, R.W., 1997. The proper scope of government: Theory and an application to prisons. Quarterly Journal of Economics $112,1127-1161$.

Hermalin, B.E., Katz, M.L., 1993. Judicial modifications of contracts between sophisticated parties: A more complete view of incomplete contracts and their breach. Journal of Law, Economics, and Organization 9, 230-255.

Holmström, B., 1982. Moral hazard in teams. Bell Journal of Economics 13, 324-340. 
Hoppe, E.I., Schmitz, P.W., 2009. Can contracts solve the hold-up problem? Experimental evidence. CEPR Discussion Paper No. 7205.

Hoppe, E.I., Schmitz, P.W., 2010a. Public versus private ownership: Quantity contracts and the allocation of investment tasks. Journal of Public Economics 94, 258-268.

Hoppe, E.I., Schmitz, P.W., 2010b. Public-private partnerships versus traditional procurement: Innovation incentives and information gathering. CEPR Discussion Paper No. 7681.

Jehiel, P., Moldovanu, B., 2006. Allocative and informational externalities in auctions and related mechanisms. In: The Proceedings of the 9th World Congress of the Econometric Society. Edited by Blundell, R., Newey, W. and Persson, T. Cambridge University Press.

Kessler, A.S., Lülfesmann, C., 2006. The theory of human capital revisited: On the interaction of general and specific investments. Economic Journal 116, 903-923.

Klibanoff, P., Morduch, J., 1995. Decentralization, externalities and efficiency. Review of Economic Studies 62, 223-247.

Konakayama, A., Mitsui, T., Watanabe, S., 1986. Efficient contracting with reliance and a damage measure. Rand Journal of Economics 17, 450-457.

Krishna, V., Perry, M. 1998. Efficient mechanism design. Discussion Paper.

Laffont, J.-J., Martimort, D., 2002. The Theory of Incentives: The PrincipalAgent Model. Princeton, N.J.

Lyon, T.P., Rasmusen, E., 2004. Buyer option contracts restored: renegotiation, inefficient threats, and the hold-up problem. Journal of Law, Economics, and Organization 20, 148-169.

Maskin, E., Moore, J., 1999. Implementation and renegotiation. Review of Economic Studies 66, 39-56.

Maskin, E., Tirole, J., 1999. Unforeseen contingencies, property rights, and incomplete contracts. Review of Economic Studies 66, 83-114. 
Matsuo, T., 1989. On incentive compatible, individually rational, and ex post efficient mechanisms for bilateral trading. Journal of Economic Theory 49, 189-194.

Mezzetti, C., 2004. Mechanism design with interdependent valuations: Efficiency. Econometrica 72, 1617-1626.

Myerson, R.B., 1982. Optimal coordination mechanisms in generalized principalagent problems. Journal of Mathematical Economics 10, 67-81.

Myerson, R.B., 1985. Analysis of two bargaining problems with incomplete information. In: Game Theoretic Models of Bargaining, A. Roth (ed.), Cambridge University Press, London, pp. 115-147.

Myerson, R.B., Satterthwaite, M.A., 1983. Efficient mechanisms for bilateral trading. Journal of Economic Theory 29, 265-281.

Rogerson, W.P., 1992. Contractual solutions to the hold-up problem. Review of Economic Studies 59, 774-794.

Rosenkranz, S., Schmitz, P.W., 2003. Optimal allocation of ownership rights in dynamic R\&D alliances. Games and Economic Behavior 43, 153-173.

Rubinstein, A., Wolinsky, A., 1992. Renegotiation-proof implementation and time preferences. American Economic Review 82, 600-614.

Samuelson, W.F., 1984. Bargaining under asymmetric information. Econometrica $52,995-1005$.

Schmitz, P.W., 2001. The hold-up problem and incomplete contracts: A survey of recent topics in contract theory. Bulletin of Economic Research 53, 2001, $1-17$.

Schmitz, P.W., 2002a. Simple contracts, renegotiation under asymmetric information, and the hold-up problem. European Economic Review 46, 169188.

Schmitz, P.W., 2002b. On the interplay of hidden action and hidden information in simple bilateral trading problems. Journal of Economic Theory $103,444-460$. 
Schmitz, P.W., 2005. Should contractual clauses that forbid renegotiation always be enforced? Journal of Law, Economics, and Organization 21, 315329 .

Schmitz, P.W., 2006. Information gathering, transaction costs, and the property rights approach. American Economic Review 96, 422-434.

Schmitz, P.W., 2008a. Incomplete contracts, the hold-up problem, and asymmetric information. Economics Letters 99, 119-122.

Schmitz, P.W., 2008b. Joint ownership and the hold-up problem under asymmetric information. Economics Letters 99, 577-580.

Schmitz, P.W., 2008c. Information gathering and the hold-up problem in a complete contracting framework. Economics Letters 101, 268-271.

Schwartz, A., 1998. Incomplete contracts. In: The New Palgrave Dictionary of Economics and the Law. Macmillan Publishers, London.

Schweizer, U., 2006. Universal possibility and impossibility results. Games and Economic Behavior 57, 73-85.

Segal, I., Whinston, M.D., 2010. A simple status quo that assures participation (with application to efficient bargaining), Discussion Paper.

Stremitzer, A., 2010. Standard breach remedies, quality thresholds, and cooperative investments. Columbia Law and Economics Working Paper No. 335.

Tirole, J., 1999. Incomplete contracts: Where do we stand? Econometrica 67, $741-781$.

Williams, S.R., 1999. A characterization of efficient, bayesian incentive compatible mechanisms. Economic Theory 14, 155-180.

Williamson, O.E., 2000. The new institutional economics: taking stock, looking ahead. Journal of Economic Literature 38, 595-613.

Williamson, O.E., 2002. The theory of the firm as governance structure: from choice to contract. Journal of Economic Perspectives 16, 171-195. 